\title{
A Identificação e a Constituição do Sujeito
}

The subject's identification and constitution

Resumo: Este trabalho tem como objetivo traçar o percurso discursivo em Freud e Lacan, principalmente em seu Seminário IX, inédito, "A Identificação", como um fenômeno importante para demarcar a constituição do sujeito .

Palavras-Chave: Identificação, sujeito, eu, Lacan, Freud.

Abstract: The aim of this work is to outline Freud and Lacan's discursive course, mainly Lacan's original Seminar IX, "The Identification" as an important phenomenon to trace the constitution of the subject. Key Words: Identification, subject, I, Lacan, Freud.

\section{Andréia da Silva Stenner}

Especialista em Psicanálise pelo CES/JF Especialista em Saúde Mental pela Esmig/MG. Mestranda em Teoria Psicanalítica -UFRJ.

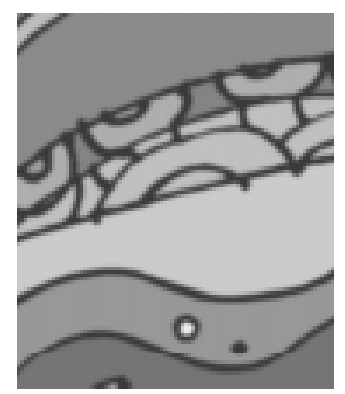

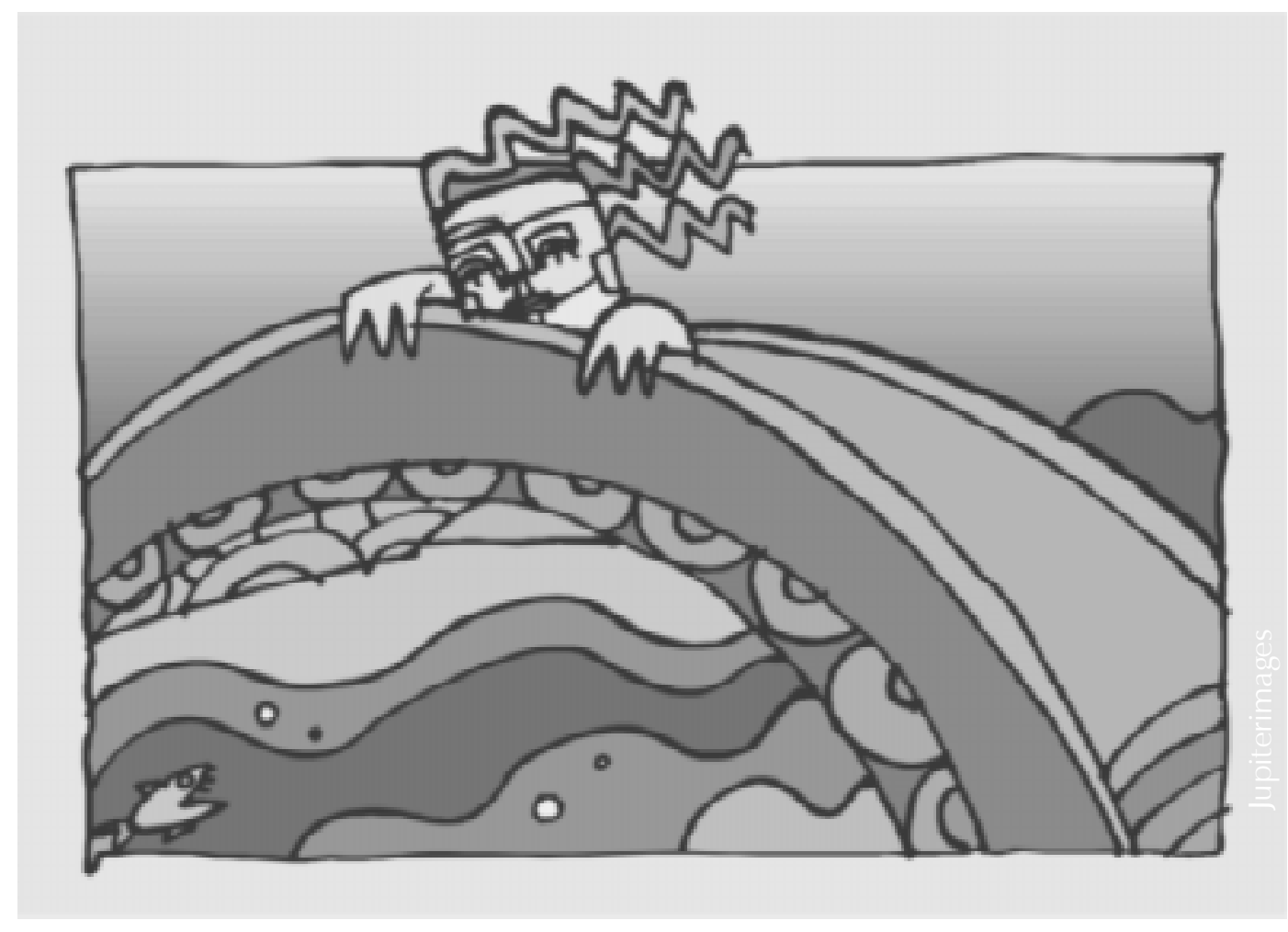

Para se pensar a constituição do sujeito, é necessário abordar o fenômeno da identificação, formulado na construção freudiana e estabelecido em Lacan, principalmente, no Seminário 9 que trata desse tema. A noção de identificação aparece em vários textos ao longo da obra de Freud, desdobrando-se em identificações que irão demarcar o eu como instância identificatória. Lacan retoma a identificação com o estatuto do nome próprio a partir do traço unário.

Portanto, neste trabalho, trataremos do tema da identificação a partir da constituição do eu em Freud e da atribuição posterior de Lacan para a identificação, como identificação ao significante, postulada em O Seminário, livro 9, "A Identificação" (1961-62).

\section{O Percurso Freudiano}

Desde seus primeiros escritos, Freud, na construção do aparelho psíquico, circunscreve, nomea e institui o eu a partir da experiência primária de satisfação. Em " O Projeto Para uma Psicologia Científica" (1895), Freud irá denominar que o eu consiste, originalmente, de neurônios nucleares, que recebem "Qn" endógenas e as descarregam, $\mathrm{e}$ cuja função é inibir a descarga quando não há 
objeto a partir dos signos percebidos, o que ele denomina atenção psíquica e defesa primária. $\mathrm{O}$ eu constituiria a totalidade dos investimentos, das séries de prazer e desprazer, a partir da experiência primária de satisfação. A não-coincidência entre percepção e o acúmulo de excitações endógenas do bebê trariam como efeito a alucinação do objeto desejado, o que causaria, segundo Freud, a existência permanente de um corpo de neurônios catexizados, constituindo a base fisiológica do eu.

Nessa identificação inaugural, verifica-se um desencontro entre o desamparo inicial, o estado de urgência e o objeto original que se perdeu, que é, na verdade, mítico, onde o que é permanente são os traços, os trilhamentos, os caminhos, que irão se instaurar e se inscrever no aparelho psíquico, criando a memória e o próprio inconsciente. Não se trata, aqui, de conceituar o inconsciente, objeto de um outro estudo, mas de pensá-lo a partir da segunda tópica para a construção do processo identificatório. Se, nesse momento, o eu surge a partir de seus investimentos no mundo externo, em busca de satisfação, criando uma identidade de memória, trilhamentos, traços e facilitações, é a partir do texto "Sobre o Narcisismo: uma Introdução"(1914) que o eu também se torna objeto de investimento, ou seja, o eu é também um objeto, o que, de certa forma, já havia sido anteriormente trabalhado em "Os Três Ensaios Sobre a Teoria da Sexualidade" (1905). Nesse texto, de 1905, Freud traz o conceito de auto-erotismo, que faz do corpo um objeto de investimentos.

As conclusões sobre o narcisismo irão dar-se a partir das investigações clínicas. Através da doença orgânica, da hipocondria e da vida amorosa, é que Freud observou e pôde se apropriar do conceito de narcisismo e pensar, formalizando-os posteriormente, os fenômenos identificatórios.

Na doença orgânica, “...o homem enfermo retira suas catexias libidinais de volta para seu próprio eu" (Freud, 1914, p.89). A hipocondria também traduz a retirada da libido dos objetos do mundo externo, concentrando-a em um órgão catexizado. A descrição clínica da esquizofrenia, como exemplifica Freud, irá demonstrar que houve um desinvestimento da libido de pessoas e coisas do mundo externo, retirando-se para o eu. É o que atesta o fenômeno da megalomania, que não constitui uma criação nova, pelo contrário, é, como sabemos, ampliação e manifestação mais clara de uma condição que já existia, o que leva a considerar o narcisismo - que surge através da indução de catexias objetais- como secundário.

$\mathrm{Na}$ vida amorosa, Freud irá falar das primeiras escolhas amorosas de uma criança, entre as pessoas que se preocupam com sua alimentação, cuidados e proteção, o que irá resultar na escolha anaclítica (a mulher que alimenta, o homem que protege) ou a escolha narcisista, onde procura a si mesma como um objeto amoroso (o que ela própria é ou foi). É também pela via narcísica que surge o "eu ideal", portanto, concerne precisamente ao que Freud chamou de "eu real", ou seja, aquele narcisismo infantil caracterizado pela autosuficiência. Esse estado narcísico é temporário. O julgamento suscitado pelas críticas dos pais, pelas censuras dos educadores e da sociedade em geral vai desfazer, progressivamente, esse estado de autosuficiência. $O$ sujeito que reluta em renunciar a essa primeira forma de satisfação procura, então, resgatá-la através de um novo ideal, a saber, o "ideal do eu", que será assimilado à instância do supereu, onde as funções de auto-observação, julgamento e censura aumentam as exigências do eu e favorecem o recalque. Mais tarde, isso será desenvolvido no texto "O Eu e o isso" (1923).

Nesse sentido, a partir de 1914, Freud faz do narcisismo uma forma de investimento pulsional necessária à vida objetiva, tornando-se um dado estrutural do sujeito. A introdução do narcisismo acarreta, quanto à definição do eu, o seu nãosurgimento desde logo, nem mesmo como resultado de uma diferenciação progressiva, mas que exige, para se constituir, "uma nova ação psíquica".

Esse texto de 1914 propõe uma primeira virada, que irá culminar com a formulação do "O Eu e o Isso" (1923) da segunda tópica freudiana:o eu, isso e o supereu. As atribuições do eu seriam: operar o recalcamento, sede da resistência, gerir a relação "princípio do prazer e realidade" e a participação da censura pela via do supereu. Freud define, nesse texto, que o supereu não é simplesmente um resíduo das primeiras escolhas objetais do isso, mas também representa uma formação reativa enérgica contra essas escolhas, já que ao: "você deveria ser assim como seu pai", implica dizer: "você não pode ser como ele, fazer tudo o que ele faz, certas coisas são prerrogativas dele". Daí é que advém seu caráter repressor. Freud irá considerar que a libido não está mais no eu, e, sim, acumulada no isso, e que o eu se apodera dela tentando impor-se ao isso como objeto amoroso. Portanto, o narcisismo do eu é um narcisismo secundário, que foi retirado dos objetos, como bem demonstraram os exemplos clínicos de Freud em 1914.

Em seu texto de 1923, Freud situa o eu a serviço de três senhores e, conseqüentemente, ameaçado por três perigos: o mundo externo, a libido do isso e a severidade do supereu. E, mais, se antes o eu era 
muito mais considerado como um grande reservatório de libido, de onde ela era enviada para os objetos, e também recebia parte da libido que refluía dos objetos, é a partir da 2 a tópica que o eu intervém como agente de defesa, o supereu como agente das interdições e o isso como pólo pulsional. $\mathrm{O} e u$, a partir dessa descrição, é, em grande parte, inconsciente, e o isso passa a ser o reservatório primeiro de energia psíquica onde se defrontam as pulsões. Assim, o inconsciente não é mais abordado como um sistema, mas como uma propriedade do isso. Sem recalcamento, não há inconsciente, como teoriza a primeira tópica, mas, sem o isso inconsciente, não há psiquismo que constitua seu primeiro furo originário.

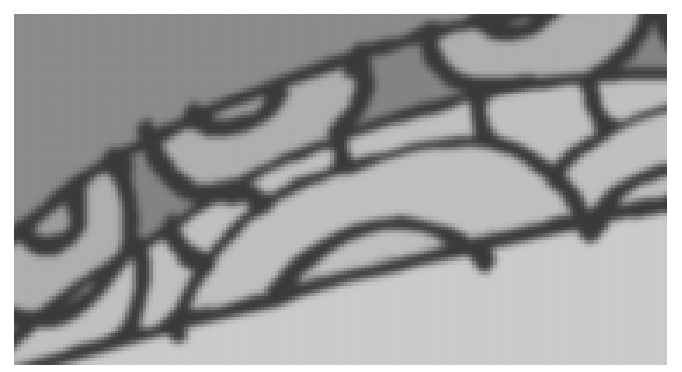

O supereu é a grande inovação da 2a tópica. Ele inibe nossos atos ou provoca remorsos, e é considerado por Freud como a instância judiciária do nosso psiquismo. O supereu aparece como defesa primária - inibição - no Projeto (1895) e sob a forma de censura do sonho. O papel interditor do supereu foi, primeiro, representado por uma potência externa, pela autoridade parental. A criança não possui inibições internas, obedece aos seus impulsos aspirando apenas ao prazer.

O eu, inicialmente "fraco", no dizer de Freud, dáse conta dos investimentos objetais, sujeita-se ou desvia-se pelo recalque e, nesse sentido, o caráter do eu é um precipitado de catexias objetais abandonadas, e, o mais importante, traz como inscrição, marca, traços, a história dessas escolhas de objeto.

Quando o eu assume as características do objeto, está forçando-se ao isso como um objeto de amor e tentando compensar a perda do isso, dizendo que pode amá-lo por ser semelhante ao objeto pela via da identificação.

Essa possibilidade, explicada anteriormente pela teoria do narcisismo, que toma o eu como objeto de investimento dando origem aos seus desdobramentos, é o que ele aponta como ideal identificação ao pai. A idéia do supereu, lançada no narcisismo, havia sido trabalhada no "Totem e Tabu" (1913), quando Freud explicou a origem da civilização pela morte do pai, que instaura a lei, e sua conseqüente identificação com ele. Se, na horda primitiva, o pai, detentor de todas as mulheres, é morto e incorporado, gerando o tabu e as proibições, é sobre essas proibições - a do incesto - que se funda a civilização, onde o ódio ao pai está na origem, e é do remorso sentido devido ao ódio e à morte do pai que nascem todos os interditos sociais. O pai morto, que se tornou mais forte do que quando vivo, instaura uma lei que possibilita a existência de um clã fraterno, onde a identificação por incorporação a esse pai, elevado ao lugar de ideal, é o que permite a coesão do grupo, mesmo que às custas de um mal-estar.

Em “Psicologia das Massas e a Análise do Eu” (1921), a partir da pergunta sobre o modo como um grupo se forma e sua capacidade de exercer influência na vida das pessoas, Freud encontra a pulsão pela via do 'amor' como a que promove laços, laços que só se fornecem pela via da identificação, o seja, a libido retorna ao eu para investir nos objetos narcisicamente.

O amor por si mesmo só conhece uma barreira, o amor pelos objetos,e é pela via da identificação que esses objetos são incorporados ao eu, ou seja, são escolhas narcísicas, não havendo uma oposição entre o eu e o objeto, pois Freud irá dizer mesmo que a identificação constitui a forma original de laço emocional com o objeto, e essa identificação só se torna possível porque o sujeito abandona seu "ideal do eu" e o substitui pelo ideal do grupo corporificado na figura do líder, uma identificação ao ideal paterno. Nesse sentido, o supereu é, inicialmente, a primeira identificação, e ele irá conservar pela vida esse caráter, conferido em sua origem no complexo paterno, diz Freud. A renúncia às satisfações pulsionais será a conseqüência para não perder o amor dessa autoridade externa, e é a partir dessa renúncia que a civilização surge. No capítulo VII , que trata especificamente da identificação, Freud traz três formas de identificação: como um laço emocional com um objeto, ligado à idéia da incorporação ao pai mítico; como uma regressão mediante um traço- o que nos aponta a psicose - e como uma qualidade compartilhada com alguém, como a histeria tão bem demonstra.

Como já abordamos anteriormente a relação da identificação com o pai, tratemos, pois, da identificação regressiva e histérica. É interessante pensar que a formalização do conceito de narcisismo tenha tido origem na percepção de Freud em relação aos mecanismos esquizofrênicos, onde o eu fica totalmente investido, como atesta a 
megalomania, com o engrandecimento do eu. Já na melancolia, Freud, no texto "Luto e Melancolia"(1917), traz o abandono do investimento objetal, onde não há identificação a um traço do objeto perdido. "A Sombra do Objeto Caiu Sobre o Eu" (Freud 1917, p. 281). A partir daí, pôde-se pensar a identificação regressiva e também como sendo sempre parcial. O que a melancolia mostra, ao contrário de um processo de luto normal, é que, ao invés de o sujeito identificar-se parcialmente como objeto perdido, ou seja, com traços, ele se torna o próprio objeto em sua radicalidade, diferentemente da neurose, como Freud trouxe no trabalho com a histeria. Em "A Interpretação dos Sonhos" (1900), ele traz, ao relatar o sonho da "bela açougueira" (Freud 1900, p.161), o estatuto da identificação histérica. O sonho de sua paciente, que contrariava aparentemente a sua tese de que o sonho é uma realização de desejo, acaba adquirindo uma nova interpretação, na qual Freud detecta a identificação de sua paciente com uma amiga, o que o leva a questionar o sentido dessa identificação:

"Qual o sentido da identificação histérica ? (...)Dirão que isso não passa da conhecida imitação histérica, da capacidade dos histéricos de imitarem quaisquer sintomas de outras pessoas que possam ter despertado sua atenção-solidariedade, por assim dizer, intensificada até o ponto da reprodução. Isso, porém, não faz mais do que indicar-nos a trilha percorrida pelo processo psíquico da imitação histérica. Essa trilha é diferente do ato mental que se processa ao longo dela. Esse é um pouco mais complicado do que o quadro comum da imitação histérica" (Freud 1900, p. 163).

È exatamente por não se tratar de uma imitação que, contrariamente a qualquer noção psicológica que se possa ter, a Psicanálise traz a identificação como um traço, como um processo que constitui e instaura o aparato psíquico e o eu ou o sujeito, cuja nova ação psíquica necessita de um ideal que, por ser mítico, opera enquanto significante. É assim que Lacan resgata do texto freudiano, a partir do Caso Dora (Freud 1905[1901]), que toma emprestado do pai sua tosse, um traço, ein einziger Zug , o traço único, ou, como dele se apropria e nomeia Lacan, o traço unário.

\section{O Percurso Lacaniano}

A noção de identificação freudiana, retomada em O Seminário, livro 9, de Lacan (1961-62), elucidarnos-á sobre o estatuto do nome na constituição do sujeito pela via do traço unário. Lacan inicia $O$ Seminário, livro 9 (1961-62), sobre a identificação, dizendo que irá falar da identificação de forma diferente da abordada anteriormente, que chamou de mítica. Ele retoma a identificação histérica definida por Freud como diferente de uma imitação ou mesmo diferente do pensamento de que a identificação seria uma referência pura e simples a um outro ao qual nos identificamos. Ela é identificação ao significante.

É nessa via que Lacan relê Freud em seu percurso das identificações e aponta a identificação ao traço, ao einzinger Zug, como o que possibilita a própria cadeia significante ou a instauração do

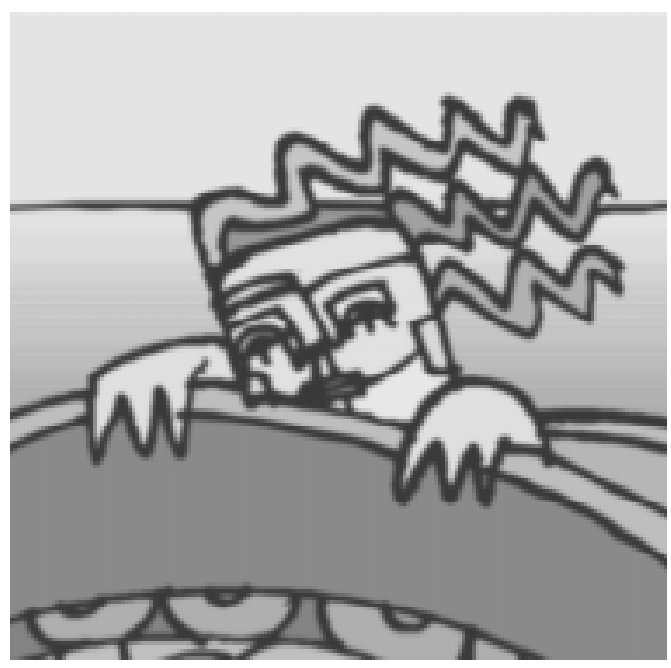

" A fundação do um que constitui esse traço não é em nenhuma parte tomada noutro lugar senão em sua unicidade: como tal, não se pode dizer dele outra coisa senão que ele é o que tem de comum todo significante, de ser, antes de tudo, constituído como traço, por ter esse traço por suporte"

"Lacan"

sujeito do inconsciente, sustentando, então, ao ponto não-mítico, a identificação inaugural ao traço como a identificação ao ideal do eu. Tratase de um traço único, como diz Lacan, absolutamente despersonalizado.

" A fundação do um que constitui esse traço não é em nenhuma parte tomada noutro lugar senão em sua unicidade: como tal, não se pode dizer dele outra coisa senão que ele é o que tem de comum todo significante, de ser, antes de tudo, constituído como traço, por ter esse traço por suporte" (Lacan 22/11/61).

Enquanto Freud traz a clínica como pano de fundo para as suas observações, Lacan traz o exemplo de sua cadela Justine, onde a relação com o outro não lhe permite fazer da linguagem um ponto de identificação que a represente enquanto sujeito, ou seja, ela pode reconhecer seu dono no plano imaginário, mas não sabemos onde ela se identifica.

"É justamente aqui que aparece a função, o valor do significante como tal, e é na própria medida em que é do sujeito que se trata que temos de nos interrogar sobre a relação dessa identificação do sujeito com o que é uma dimensão diferente de tudo o que é da ordem da aparição e do desaparecimento, ou seja, o estatuto do significante "(Lacan 6/12/61). 
Nesse sentido, no plano imaginário ou do outro, a identificação estaria ligada ao aparecimento e desaparecimento, o fort-da freudiano, mas tratase de uma outra ordem, trata-se, mesmo, do significante, o que ele exemplifica no caso Hans quando o mesmo elege - frente a uma suspensão radical do desejo da mãe - um significante que o preserva no mínimo de centragem de seu ser e, ao mesmo tempo, o protege de ficar à deriva do capricho materno. Lacan continua em sua releitura de Freud apontando os três tipos de identificação: a regressiva, a identificação ao pai, por incorporação, e a histérica, pela via do desejo.

Ao diferenciar o sujeito do significante, Lacan traz o estatuto do nome próprio para falar da identificação, nome que vale por sua função distintiva em sua materialidadade sonora, e cuja função para o sujeito, na linguagem, é nomeá-lo diante de uma bateria significante.

Ao se reapropriar da linguagem de Saussure, Lacan caracteriza o significante como diferença apoiada na função da unidade, entendida como função do UM, não no sentido de unificação, mas de unicidade, ou seja, referindo-se a um traço puramente distintivo; é exatamente isso que irá constituir o sujeito em sua relação com o Outro - o inconsciente, tesouro do significante - a partir do qual só se pode fazer representar por um significante, retirado como traço desse Outro.

O que esse traço carrega é, na verdade, o suposto encontro com o objeto: “(...) se é do objeto que o traço surge, de algo do objeto que o traço retém, justamente sua unicidade, o apagamento, a destruição absoluta de todas essas outras emergências..."(Lacan 24/01/62).

Assim, a identificação ao traço aponta para uma falta, nesse desencontro inaugural que constitui o sujeito, como o demonstrou o Projeto (1895). A repetição surge, então, como repetição significante, na tentativa de restabelecer ou restaurar esse momento mítico no que ele tem de unicidade; não se trata de um eu-síntese, mas de um eu que se constitui como des-ser, como faltoso.

Nesse sentido, o trilhamento escolhido nesse trabalho vem apontar-nos o eu como o lugar das identificações onde o sujeito se relaciona a partir de uma falta e busca sua unidade de ser numa relação que será sempre dissimétrica. Essa identificação dá-se por um assujeitamento à lei, a uma lei internalizada pela via do ideal do eu. abre ao sujeito a possibilidade de saída do campo narcísico, onde a identificação às insígnias do pai, instaurando a interdição do incesto simbólica, dá origem à civilização, ao se ver privada por uma renúncia pulsional que Freud e Lacan assinalam como inerente ao campo do sujeito. A "bela açougueira" (1900), privada em seu sonho do que mais gosta, o caviar, identifica-se com a privação de sua amiga de seu objeto predileto, o salmão.

O elemento novo, trazido por Lacan, que se inscreve na identificação freudiana, ainda estaria por vir em O Seminário, livro 10(1962-63): é o objeto a. Nessa etapa de sua elaboração, Lacan ainda não contava com a conceituação do objeto a, mas não se pode deixar de concluir que a identificação surge a partir de uma operação cujo resto é o objeto a, que aponta para uma falta constitutiva no sujeito e no Outro.

"Como indiquei ontem à noite, o objeto metonímico do desejo, o que em todos os objetos representa esse pequeno a eletivo, onde o objeto se perde, quando esse objeto surge como metafórico, quando chegamos a substituí-lo ao sujeito, que, na demanda, chega a se sincopar, a desaparecer, a ausência de marca; o significante desse sujeito nós o revelamos, damo-lhe seu nome(...)"( Lacan, 29/11/61).

$\mathrm{Na}$ verdade, trata-se da identificação a uma falta no Outro. É a falta no Outro, tomada como objeto, frente a uma perda, que viabiliza ao sujeito poder advir no Outro a partir das identificações. Em $O$ Seminário, livro 11(1964), Lacan traz a falta para o campo do sujeito e do Outro. A falta tem uma dupla inscrição. Por um lado, ela advém do fato de o sujeito depender de um significante que está primeiro no Outro; por outro lado, ela é o que o sujeito perde em sua entrada na linguagem. O que Lacan dirá, de outra forma, é que não há no campo do Outro, nem no campo do sujeito, um significante que dê conta do ser, da mulher, da morte, e, portanto, a falta é condição de inscrição para todo ser de linguagem. 
Andréia da Silva Stenner

Rua Renato Dias, 600/302 - São Mateus Cidade: Juiz de Fora - MG. 36010-011

Tel.: (032) 3226-5438

celular:(032) 99375422

E-mail:andreia_stenner@bol.com.br

FREUD, S.Projeto Para uma Psicologia Científica. ESB, vol.I. Rio de Janeiro: Imago Editora, 1990(1895).

FREUD, S. A Interpretação dos Sonhos. ESB, vol.IV. Rio de Janeiro: Imago Editora, 1990(1900).

FREUD, S. Três Ensaios Sobre a Teoria da Sexualidade. ESB, vol.VII. Rio de Janeiro: Imago Editora, 1990(1905).

FREUD, S. Fragmento da Análise de um Caso de Histeria. ESB, vol. VII. Rio de Janeiro: Imago Editora, 1990(1905[1901]).

FREUD, S. Totem e Tabu. ESB,vol.XIII. Rio de Janeiro: Imago Editora, 1990(1913[1912-13]).

FREUD,S.Sobre o Narcisimo: uma Introdução. ESB, vol.XIV. Rio de Janeiro: Imago Editora, 1990(1914).

FREUD, S.Luto e Melancolia. ESB,vol.XIV. Rio de Janeiro: Imago Editora, 1990(1917[1915]).

FREUD,S. Psicologia de Grupo e Análise do Ego. ESB, vol.XVII. Rio de Janeiro: Imago Editora, 1990(1921).

Referências

FREUD, S. O Eu e o Isso. ESB, Vol.XIX. Rio de Janeiro, Imago Ed., 1990(1923).

FREUD, S. O Mal-estar na Civilização. ESB, Vol.XXI . Rio de Janeiro: Imago Ed., 1990(1930[1929].

LACAN, J. A Identificação. In O Seminário, livro 9, inédito, 1961-2.

LACAN, J. A Angústia. In O Seminário, livro 10, inédito(1962-3).

LACAN, J. Os Quatro Conceitos Fundamentais da

Psicanálise.In. O Seminário, livro 11 .Rio de Janeiro: Jorge

Zahar,1988(1964) 